\title{
DOS INTERPRETACIONES DE (YO) CREO (QUE) Y SU USO ATENUANTE-INTENSIFICADOR
}

\author{
TWO INTERPRETATIONS OF (YO) CREO (QUE) AND ITS \\ MITIGATING-INTENSIFYING USE
}

\author{
YU XIE \\ Universidad de Sichuan \\ xieyu1114@scu.edu.cn
}

Enviado: 25/01/2019

Aceptado: 22/05/2019

\section{Resumen}

Las expresiones de la modalidad epistémica pueden indicar la actitud del hablante sobre la verdad de lo enunciado. Además, son recursos estratégicos eficaces que utiliza el hablante para conseguir su fin comunicativo en determinados contextos. Su uso inadecuado o la falta de uso pueden provocar efectos descorteses.

En el presente artículo seguimos el modelo de Arndt (1987), que plantea dos significados básicos de (yo) creo (que): creencia/evidencia insuficiente y actitud/opinión personal. Para el análisis de las dos interpretaciones de la construcción, contamos con el Corpus de Español, del cual se extraen los ejemplos textuales de este trabajo para obtener los cálculos estadísticos con los que descubrimos las tendencias de uso. Aparte del análisis cuantitativo, recurrimos al estudio cualitativo para estudiar (yo) creo (que) en contextos comunicativos concretos y analizar sus valores pragmáticos, en concreto, su aportación para la cortesía y la imagen social de los interlocutores. Los resultados del análisis

\begin{abstract}
The expressions of epistemic modality can indicate the attitude of the speaker about the truth of the statement. In addition, they are effective strategic resources that the speaker uses to achieve their communicative purpose in certain contexts. Improper use or lack of use can lead to impolite effects.

In the present article, we follow Arndt's model (1987) which raises two basic meanings of (yo) creo (que): belief / insufficient evidence and attitude / personal opinion. For the analysis of the two interpretations of the construction, we use the Corpus of Spanish to extract the textual examples of this work in order to obtain the statistical calculations with which we discover the use tendency. In addition to the quantitative analysis, we resort to the qualitative study to analyse (yo) creo (que) in concrete communicative contexts and discuss their pragmatic values, in particular, their contribution to the courtesy and the social image of the interlocutors. The results of the analysis allow us to affirm that
\end{abstract}

Para citar este artículo / To cite this article: Xie, Yu (2019). Dos interpretaciones de (yo) creo (que) y su uso atenuante-intensificador. ELUA, 33: 211-231. doi: 10.14198/ELUA0000.33.11

Enlace / Link: http://dx.doi.org/10.14198/ELUA0000.33.11 
nos permiten afirmar que (yo) creo (que) puede producir efectos epistémicos en muchos contextos, mientras experimenta una pérdida total del valor epistémico y se convierte en elemento meramente cortés en otros. Además, hay casos en los que se pueden percibir las dos interpretaciones en un mismo contexto.

Por otro lado, logramos sacar la conclusión de que, contextualmente, la construcción (yo) creo (que) puede tener tanto uso atenuate como intensificador. Se usa principalmente para la atenuación, tanto en su función de "modal epistémico", que indica un bajo grado de certeza como en la de "modalizador de opinión", que funciona como recurso capaz de atender las necesidades de cortesía. Además, esta unidad puede adquirir un valor intensificador cuando expresa opiniones que benefician la imagen social del interlocutor.

PALABRAS CLAVE: modalidad epistémica, dos interpretaciones de (yo) creo (que), uso intensificador, uso atenuante, cortesía. (yo) creo (que) can produce epistemic effects in many contexts while experiencing a total loss of epistemic value and becoming a polite resourse in other cases. In addition, there are cases in which the two interpretations can be perceived in the same context.

On the other hand, we managed to draw the conclusion that contextually (yo) creo (que) can indicate mitigation and intensification. It is used mainly for the mitigation both in its function of "epistemic modal" —which represents a low degree of certainty - and in the function of "modalizer of opinion" — which works as a resource capable of attending to the needs of politeness-. Furthermore, this marker can acquire the quality of intensification when it expresses opinions that benefit the social image of the interlocutor.

KEYWORDS: epistemic modality, two interpretations of (yo) creo (que), mitigating use, intensifying use, politeness.

\section{INTRODUCCIÓN: DESCRIPCIÓN DE (YO) CREO (QUE) Y EL OBJETIVO DE NUESTRO ESTUDIO}

Creer es un verbo de actitud proposicional, a través del cual se refleja un proceso cognitivo y subjetivo que lleva a cabo el sujeto conceptualizador. Aunque (yo) creo (que) puede tener distintas interpretaciones según diferentes contextos, siempre expresa un significado básico de que lo que enuncia forma parte del conocimiento o creencia del hablante. Este verbo, junto con otros, tales como pensar, imaginar, suponer, etc., han sido etiquetados con diversas denominaciones teniendo en cuenta sus rasgos pragmáticos: "verbos de opinión" (García Miguel y Comesaña 2004), “predicados asertivos débiles” (Hooper 1975), "verbos de afirmaciones atenuadas" (Borrego et alii 1990), etc. Todas estas denominaciones nos están revelando los rasgos más importantes de este verbo: se trata de un recurso para la expresión de opinión y la indicación de no certeza.

Arndt (1987) se centra en el valor de (yo) creo (que) y lo clasifica en dos tipos: creencia/ evidencia insuficiente y opinión/actitud personal. Muchos autores (De Saeger 2006; Fuentes 2010a, entre otros) señalan en su estudio los dos significados de creer en su uso como verbo performativo (primera persona del presente de indicativo). Como se indica en la tabla 1, sus rasgos diferenciadores son:

Este estudio ha sido una base importante para nuestro análisis. A partir de los dos significados de Arndt (1987), estudiaremos en la sección 3 dos interpretaciones de (yo) creo (que).

En el ámbito de estudio de la intensificación y la atenuación, (yo) creo (que) suele estudiarse como recurso para esta última estrategia (Meyer-Hermann 1988; Albelda \& Mancera 2011; Soler Bonafont 2018), aunque también hay escasos estudios que se centran en el valor 


\begin{tabular}{|c|c|c|}
\hline & $\begin{array}{l}\text { Creencia/evidencia insuficiente } \\
\text { (Arndt 1987) }\end{array}$ & $\begin{array}{l}\text { Actitud/opinión personal } \\
\text { (Arndt 1987) }\end{array}$ \\
\hline Definición & $\begin{array}{l}\text { "Tener algo por verosímil o probable" } \\
\text { (RAE). En otras palabras, se expresa } \\
\text { la posibilidad de que algo ocurra o } \\
\text { la falta de seguridad del hablante } \\
\text { sobre la realización de lo dicho, su } \\
\text { incertidumbre. } \\
\text { De acuerdo con Haverkate (1994), } \\
\text { el predicado cognitivo, como creer, } \\
\text { ocupa la zona intermedia en la escala } \\
\text { epistémica, es decir, entre los asertivos } \\
\text { y los dubitativos. Se usa para indicar } \\
\text { la estimación del hablante de la } \\
\text { posibilidad de que una proposición (p) } \\
\text { sea verdadera. }\end{array}$ & $\begin{array}{l}\text { Según la RAE, denota el significado de } \\
\text { "pensar u opinar algo". Se trata de un } \\
\text { marcador asertivo. }\end{array}$ \\
\hline Características & $\begin{array}{l}\text { - Modaliza el contenido proposicional. } \\
\text { - Expresa incertidumbre sobre la ver- } \\
\text { dad del contenido proposicional. } \\
\text { - No hay valoración. } \\
\text { - Es un marcador modal. }\end{array}$ & $\begin{array}{l}\text { - No afecta al contenido proposicio- } \\
\text { nal. } \\
\text { - Se admite como verdadero lo enun- } \\
\text { ciado. } \\
\text { - Hay valoración o caracterización en } \\
\text { el contenido de la proposición. } \\
\text { - Atañe a la esfera de la enunciación. }\end{array}$ \\
\hline
\end{tabular}

Tabla 1. Dos tipos de (yo) creo (que) según Arndt (1987).

de aserción intensificada de (yo) creo (que) en contextos comunicativos más específicos (Fuentes 2010a).

(Yo) creo (que) se usa frecuentemente tanto en el habla oral como en la escrita. De los 121980 ejemplos citados en el Corpus del Español (categoría Now 2012 - el mes pasado), hemos elegido aleatoriamente una totalidad de 200 ejemplos $^{1}$ para nuestro análisis.

Lo que nos interesa es estudiar separadamente los dos significados (Arndt 1987) de (yo) creo (que), ya que hay claras diferencias en el aspecto que atenúan e intensifican, sus comportamientos sintácticos, la imagen social que protegen, etc. Nuestro análisis se desarrollará en los apartados 4. y 5. Nos parece adecuado estudiar el uso atenuante e intensificador de (yo) сreo (que) en dos niveles: cuando funciona como mero marcador epistémico y cuando contiene cierto valor de cortesía. En este segundo caso, teniendo en cuenta que la mayoría de los estudios de (yo) creo (que) suelen dar descripciones muy generales sobre su valor de cortesía, pretendemos analizar detenidamente los ejemplos del corpus para explicar los distintos efectos corteses que aporta (yo) creo (que) en su uso atenuante-intensificador ${ }^{2}$.

1 Hemos revisado, antes de entrar en el análisis de (yo) creo (que), los primeros 500 ejemplos que aparecen en el corpus, teniendo en cuenta la gran repetición de uso que presentan los ejemplos con esta contrucción, hemos elegido aleatoriamente 200 para nuestro análisis, cantidad que consideramos suficiente para obtener resultados sobre la tendencia de uso y las posibles funciones de (yo) creo (que).

2 Cfr. Xye (2017), de la que se han tomado la base teórica y algunas clasificaciones. 


\section{EXPRESIONES EPISTÉMICAS, SU USO ATENUANTE-INTENSIFICADOR Y LA CORTESÍA}

Cuando hablamos de la cortesía verbal, recogemos las palabras de Fuentes (2010b: 7) que afirma que "son muchos los acercamientos, la mayoría desde una perspectiva sociopragmática, etnopragmática o intercultural, que presuponen siempre el aspecto lingüístico sin detenerse en él" y esta cortesía se centra en la elección de determinados indicadores lingüísticos de cortesía (Calsamiglia y Tusón, 2012).

La cortesía atañe a la identidad social de los participantes en un acto comunicativo, ya que una actividad comunicativa es considerada socialmente como una escena en la que los actores (interlocutores) juegan su papel.

Partiendo de una perspectiva pragmática, podemos decir que la cortesía se manifiesta a través de la modalidad, ya que mientras uno se muestra cortés con su interlocutor, siempre deja ciertas huellas de subjetividad en el mensaje, o sea, adopta alguna actitud ante el hecho.

Los recursos de la modalidad epistémica también forman una parte relevante para la expresión de la cortesía, sobre todo la estratégica (Fuentes, 2010b) ${ }^{3}$. Estos, en su uso cotidiano, no solo conciernen a la expresión del punto de vista respecto a la verdad de un hecho, sino que sirven de herramientas que puede manejar el hablante ante su necesidad de llevarse bien con los demás, de enfrentarse con determinadas situaciones comunicativas de forma adecuada y comedida, sin insultar ni frustrar a su interlocutor. Es de suma importancia tener en cuenta que la cortesía no siempre surge por la necesidad de tranquilizar ante las amenazas o de subsanar los enfrentamientos, sino que actúa como un estimulante positivo para la relación entre los participantes de la enunciación. A la vista de esto, Aquí habría que establecer una distinción, una que no tendría cabida en el modelo de Brown y Levinson (1987): la cortesía mitigadora y la cortesía valorizante ${ }^{4}$. En nuestra opinión, esta sería una clasificación más razonable e interpreta mejor el valor de la cortesía en su uso discursivo. Basándonos en ella agrupamos los recursos epistémicos en:

- Expresiones epistémicas de uso atenuante (EEA): son aquellos recursos cuya función consiste en suavizar los FTA (Brown y Levinson 1987) ${ }^{5}$ mediante la indicación de una evaluación modal de "no seguridad".

- Expresiones epistémicas de uso intensificador (EEI): son los recursos que contribuyen a efectuar los FFA (Kerbrat-Orecchioni 1996) ${ }^{6}$, es decir, al refuerzo de los efectos positivos para la imagen social del interlocutor mediante la indicación de un grado de certeza perfecta.

\footnotetext{
3 La autora (2010b) plantea dos tipos de cortesía: la cortesía ritural y la cortesía estratégica. La primera sirve para coordinar las interacciones sociales en el sentido de que regule los intercambios mecánicos entre los miembros de un acto comunicativo. Mientras, la segunda se ocupa más de proteger la imagen social, de regular y equilibrar las relaciones interpersonales.

4 La cortesía mitigadora está dirigida a las posibles amenazas que existen en el acto comunicativo. La cortesía valorizante, por su parte, surge para mantener o estrechar la relación interpersonal o, según Carrasco (1999), para crear o potenciar un efecto agradable en la interacción, sin que medie en ella un potencial de amenaza.

5 Brown y Levinson (1987) define los face threatening acts (FTA) como actos de amenaza a la imagen.

6 Kerbrat-Orecchioni (1996) define los face flattering acts (FFA) como actos de refuerzo de la imagen.
} 
Ambos tipos de recursos epistémicos son marcadores que están a disposición del hablante para perfeccionar su manera de hablar y que, como consecuencia, modifican el efecto que el enunciado tiene sobre el oyente y, sobre todo, presentan al enunciador bajo una luz favorable. La cortesía mitigadora, aunque no exclusivamente, suele manifestarse por medio de los procedimientos de atenuación lingüística (Briz, 1998), en este caso, por las EEA, que están más ligadas a ceder el control al interlocutor y no invadir el territorio ajeno. Por su parte, la cortesía valorizante suele manifestarse a través de los procedimientos de intensificación, en este caso, de las EEI ya que estas están íntimamente vinculadas con la afectividad, por medio de ellas el hablante transmite una actitud amistosa o manifiesta su posición de apoyo al interlocutor. Son recursos que el hablante tiene en su mano para aproximarse a las expectativas del interlocutor. Ambas funcionan como herramientas de relación social, para quitar tensión o para crear más armonía en el acto discursivo, de forma que se asegure el logro de algún objetivo.

Hemos comprobado (Xie, 2017) que el uso intensificador es el predominante en las expresiones epistémicas que indican alto valor de verdad, mientras el valor atenuante predomina en aquellas que expresan bajo grado de certeza. Sin embargo, hemos rechazado las correspondencias absolutas entre expresiones epistémicas de uso intensificador-recursos de refuerzo de la aserción y expresiones epistémicas de uso atenuante-recursos de suspensión de la aserción. Es importante tener claro que un mismo elemento epistémico puede usarse para las dos estrategias, atenuación e intensificación, pero en cada uno de estos usos funciona de manera distinta. Prueba de ello es el caso de (yo) creo (que): esta unidad se usa principalmente para la atenuación, pero puede adquirir un valor intensificador cuando se expresa un acuerdo o una valoración positiva, actos que benefician a la imagen social del interlocutor.

\section{DOS INTERPRETACIONES DE (YO) CREO (QUE)}

Para el análisis del (yo) creo (que), hemos recurrido al Corpus del Español como fuente principal. Entre los 200 casos de este marcador, hemos encontrado 63 ítems (31,5\%) en los que el marcador contiene un significado epistémico. En estos casos, indica la duda o la incertidumbre del hablante frente al evento o estado de cosas que está describiendo. Mientras en otros 132 ejemplos (66\%), (yo) creo (que) contiene un valor argumentativo, en muchos estos casos, carece de interpretación epistémica.

Basándonos en el modelo de Arndt (1987), que estudia los dos significados básicos de creo, establecemos también una dinstción entre dos interpretaciones de la construcción de (yo) creo (que), cuyas diferencias se desarrollan en la tabla 2:

- Modal epistémico: (yo) creo (que) 1

- Modalizador de opinión: (yo) creo (que) 2

Tanto el hecho de expresar una evaluación epistémica como el de expresar un parecer, una valoración, un comentario, etc., son reflejos del proceso cognitivo y subjetivo que lleva a cabo el sujeto conceptualizador. Sin embargo, los dos procedimientos, en su realización, ofrecen diferencias en los aspectos semánticos y sintácticos de la proposición subordinada. Por consiguiente, se generan diferentes efectos pragmáticos. 


\begin{tabular}{|c|c|c|}
\hline & $\begin{array}{l}\text { Modal epistémico } \\
\text { (yo) creo (que) } 1\end{array}$ & $\begin{array}{l}\text { Modalizador de opinión } \\
\text { (yo) creo (que) } 2\end{array}$ \\
\hline Descripción & $\begin{array}{l}\text { Enfocada a lo dicho. } \\
\text { Mantiene el valor semántico original. } \\
\text { Se expresa una evaluación sobre la } \\
\text { veracidad del contenido proposicional. } \\
\text { Ej.: Creo que va a llover. } \\
\text { Ej.: Creo que tendrá unos treinta años. } \\
\text { El rasgo de la opinión subjetiva queda } \\
\text { menos matizado cuando lo enunciado } \\
\text { representa una creencia insuficiente } \\
\text { del hablante. En lugar de expresar una } \\
\text { opinión, se manifiesta cierta creencia, } \\
\text { se da una aserción atenuada sobre la } \\
\text { veracidad del contenido proposicional. } \\
\text { Creo que se utiliza en su valor } \\
\text { epistémico de expresión de un hecho } \\
\text { del que no está seguro. }\end{array}$ & $\begin{array}{l}\text { Enfocada al decir. } \\
\text { El hablante admite como } \\
\text { verdadero lo enunciado. Lo dicho } \\
\text { puede incluir una valoración o } \\
\text { aparecer sin ella. } \\
\text { Ej.: Yo creo que Chopin es el } \\
\text { mejor músico en su época (con } \\
\text { valoración). } \\
\text { En este ejemplo, cuesta aceptar } \\
\text { que el hablante evalúa la } \\
\text { probabilidad de lo dicho con el } \\
\text { verbo creer. "Una opinión sigue } \\
\text { siendo una opinión, un evento } \\
\text { real sigue siendo, en los ojos del } \\
\text { hablante, un evento real, etc." (De } \\
\text { Saeger, 2006: 273). }\end{array}$ \\
\hline Aspecto que se atenúa & $\begin{array}{l}\text { Atenúa el contenido proposicional } \\
\text { mediante la modalidad. } \\
\text { Ej.: Creo que va a llover. } \\
\text { El contenido de la oración completiva } \\
\text { va a llover ya no es una verdad, solo } \\
\text { una posibilidad. }\end{array}$ & $\begin{array}{l}\text { Atenúa el decir, la fuerza } \\
\text { ilocutiva, los efectos negativos } \\
\text { de lo dicho. También aporta al } \\
\text { proceso de intensificación. } \\
\text { Ej.:-Yo creo que no hay } \\
\text { instrumento fácil, realmente. } \\
\text { (Habla Culta; Bogotá: M6). } \\
\text { Yo creo que solo introduce una } \\
\text { opinión personal del hablante } \\
\text { sin modificar la autencidad del } \\
\text { contenido. }\end{array}$ \\
\hline $\begin{array}{l}\text { Imagen social que se } \\
\text { protege }\end{array}$ & La imagen social del hablante. & $\begin{array}{l}\text { La imagen social del hablante y } \\
\text { del interlocutor. }\end{array}$ \\
\hline $\begin{array}{l}\text { Compromiso con lo } \\
\text { enunciado }\end{array}$ & $\begin{array}{l}\text { El hablante se aleja de la responsabi- } \\
\text { lidad de lo enunciado. No se compro- } \\
\text { mete con la verdad de lo dicho. }\end{array}$ & $\begin{array}{l}\text { El hablante intenta dejar su huella } \\
\text { en lo dicho y subraya su presencia } \\
\text { en la escena comunicativa. }\end{array}$ \\
\hline
\end{tabular}

Tabla 2. Rasgos diferenciadores de las dos interpretaciones de (yo) creo (que)

Hablando del comportamiento sintáctico, (yo) creo (que) 2 no se limita a las formas performativas, es decir, el valor argumentativo no varía con el cambio de sujeto. En "Juan cree que Chopin es el mejor músico de su época”, el verbo cree mantiene su valor argumentativo 
de expresar opinión o juicio de valor. Además, suele emplearse predominantemente en posición inicial e introduce una cláusula completiva con que. El sujeto está a menudo explícito, ya que según Aijón Oliva y Serrano (2010), la presencia de yo contribuye a subrayar la presencia de este en la escena comunicativa y a responsabilizarle del contenido que se va a tratar. Es un recurso de subjetivización del mensaje. Obviamente, usar una u otra forma lingüística es una decisión que toma el hablante teniendo en cuenta su intención comunicativa. Expresar u omitir el sujeto, en nuestra opinión, no siempre es una decisión casual del hablante. Como se muestra en la tabla siguiente, basándonos en los 200 casos de (yo) creo (que), los casos con sujeto y sin sujeto presentan la siguiente proporción:

\begin{tabular}{|l|l|l|}
\hline & Modal epistémico & Modalizador de opinión \\
\hline Expresión de sujeto & 19 casos & 78 casos \\
\hline Omisión de sujeto & 44 casos & 54 casos \\
\hline
\end{tabular}

Tabla 3. Omisión y expresión del sujeto en (yo) creo (que)

A partir de este resultado, coincidiendo con la conclusión de Aijón Oliva y Serrano (2010: 8), podemos ver que la formulación del sujeto se asocia generalmente a la expresión de opinión. Es la forma que permite al hablante subrayar su relación con su propia enunciación. Con la presencia del sujeto, marca claramente la posición del hablante en el acto verbal y facilita la expresión de una opinión personal. Esto lo podemos comprobar, sobre todo, en los contextos en los que hay mayor tensión interactiva, por ejemplo, en los que hay varios interlocutores que se disputan el turno. Este "yo" está vinculado con la responsabilidad. Como indican Aijón Oliva y Serrano (2010: 8):

La presencia del sujeto subraya, en cualquier caso, una prominencia perceptiva que sirve para enfatizar la responsabilidad del hablante del contenido de lo que se dice. [...] la presencia icónica del sujeto de primera persona asociado al verbo creer indica que el hablante asume el contenido de lo dicho y se presenta en la escena comunicativa como tal.

(Yo) creo (que)2, cuando ejerce alguna función discursiva, se ve cierta preferencia sobre la expresión y la omisión del pronombre personal yo, mientras en otras funciones, no hay una tendencia de uso muy marcada. Veamos algunos resultados estadísticos basados del análisis del corpus:

\begin{tabular}{|l|l|l|}
\hline & Expresión de sujeto & Omisión de sujeto \\
\hline Expresión de modestia & $20 \%$ & $80 \%$ \\
\hline Expresión de sugenrencia & $50 \%$ & $50 \%$ \\
\hline $\begin{array}{l}\text { Expresión de valoración ne- } \\
\text { gativa (no tiene efecto en la } \\
\text { imgen del interlocutor) }\end{array}$ & $44,4 \%$ & $55,5 \%$ \\
\hline
\end{tabular}

Tabla 4. Preferencia de uso del pronombre personal yo según funciones discursivas 
A nuestro modo de ver, expresar u omitir el pronombre personal, en muchos casos, es una desición casual del hablante, sobre todo en contextos orales. Por otro lado, elegir uno u otro recurso lingüístico hace posible al hablante indicar distintas intenciones comunivativas (reforzar su posición, dar señar de énfasis, etc.) aunque en todo caso pretenda lograr el mismo fin comunicativo. En el caso de la expresión de sugerencia, consideramos recursos apropiados tanto creo que como yo сreo que para disminuir los efectos descorteses que provoca el acto directivo. Sin embargo, en ciertos contextos, la presencia de sujeto podría tener un matiz de modestia, y con su uso resulta menos sentencioso el consejo que se da:

(1) Yo no sé cómo puede ser el modo de reducirlo. Yo creo que habría que aumentar los docentes - - - quizás sería... Enc. —Claro, poner más docentes. ¿Usted acá hace alguna tarea de docencia? Inf. - Muy poca; solamente la parte de trabajos prácticos de los alumnos. Enc. —Son [...] Inf. —Sí, todos los médicos de acá en el instituto hacemos tr... eh... de instructores de trabajos prácticos y... (Corpus del Español; Habla Culta: Buenos Aires: M6 A).

A la inversa, entendemos que la ausencia del sujeto en los casos epistémicos da una señal de que el hablante pretende alejarse de la responsabilidad sobre la veracidad de lo dicho, mostrar cierta objetividad e independencia en lo enunciado, con el fin de guardar su propia imagen social. Por consiguiente, consideramos que creo que es la fórmula que conlleva menor asertividad y fuerza pragmática.

En cuanto al comportamiento sintáctico de (yo) creo (que) 1, frecuentemente actúa con independencia sintáctica. Puede estar insertado en la oración o aparecer en distribuciones como elemento marginal del enunciado. Solo aparece en primera persona del singular del presente de indicativo (uso performativo) y en construcciones impersonales también en presente (Se cree que...). De esta forma, se anula la relación epistémica entre el sujeto y la oración subordinada. Igual que (yo) creo (que) 2, puede omitir o no el pronombre personal. Veamos algunos ejemplos de las posiciones de (yo) creo (que) 1 en el enunciado:

(2) Creo que va a venir esta noche (posición inicial).

(3) Su padre, creo yo, no recuerdo bien, es español (posición intermedia).

(4) La nueva profesora se llama Carmen, creo (posición final).

De las dos interpretaciones de (yo) creo (que), la expresión de duda indica el valor epistémico, mientras la expresión de opinión se utiliza en la argumentación. Sin embargo, queríamos dejar claro que una proposición introducida por creo que puede tener distintas interpretaciones. Por ejemplo, si el hablante dice "Creo que el español es más difícil que el inglés", caben las dos interpretaciones:

a) Creo que expresa una actitud epistémica: lo planteado es meramente una suposición del hablante. Puede que no conozca los dos idiomas o uno de ellos. Lo dicho es una posibilidad, algo no seguro.

b) Creo que introduce una opinión: el hablante no tiene incertidumbre sobre lo enunciado. Lo atenúa con creo que porque no quiere imponer la idea a los demás, tampoco quiere ser tajante. Por lo tanto, declara que lo dicho solo presenta su propia idea, sin intención de imposición. Aquí creo que puede sustituirse por digo que, en mi opinión, etc. 
A pesar de la ambigüedad, en ambas interpretaciones se dan efectos de mitigación.

\section{4. (YO) CREO (QUE) 1 COMO MODAL EPISTÉMICO}

Aijmer (1997: 18) hizo un parámetro de "reliability of knowledge" (fiabilidad del conocimiento) y puso en orden los verbos de actitud proposicional según el nivel de fiabilidad:

[High degree of reliability]

I am sure

I believe

I think

I suppose

I guess

[Low degree of reliability]

Obviamente, I think es el que comparte el mismo valor epistémico con (yo) creo (que) y está situado en el medio de la escala. Desde una perspectiva epistémica, la expresión de incertidumbre hace debilitar la argumentación, de forma que, al presentar el evento con este verbo, cambia el estatuto del contenido: "Ya no es una realidad, sino una posible realidad" (De Saeger 2006: 273). Además, según este autor, "para que sea posible la interpretación de probabilidad es necesario que la proposición sea un estado de cosas sin valoración”. En el siguiente ejemplo, aparece dos veces creo que, y la diferencia está en que el primer creo que introduce una actitud subjetiva, dando valoraciones sobre algún hecho: poco generosos. El segundo solo tiene la interpretación de probabilidad, que no implica ningún tipo de valoración subjetiva en lo que enuncia, sino una evaluación epistémica frente a un "simple estado de cosas":

(5) Creo que UCD o los bancos fueron poco generosos con el PSA, porque la campaña fue pobre, pero aun así sacaron creo que cerca de cien mil votos y dos diputados.

Sin embargo, el segundo creo que también da indicios subjetivos, ya que se vincula con usos epistémicos. A través de él se manifiesta la postura del hablante sobre el grado de (in) certidumbre que adjudica al contenido del mensaje. Este mantiene su valor original de lo epistémico. Según afirma De Saeger (2006), aquí el desliz hacia la modalidad epistémica implica una reducción. Por un lado, reduce el contenido proposicional. Con este procedimiento, se mitiga la confiabilidad de la información dada. Por otro lado, reduce la relación entre el conceptualizador y este contenido proposicional. Es decir, el hablante se aleja de la responsabilidad sobre la verdad de lo dicho para proteger la propia imagen social.

De forma análoga a I think, (yo) creo (que), cuando funciona como modal epistémico, puede presentarse como proposición principal de la oración que introduce como un complemento o como marcador epistémico que aparece entre pausas:

(6) - Hay un partido radical, hay algunos demócratas cristianos - - - un partido demócrata cri - - - cristiano disidente - - - de manera que no es el comunismo el que ha triunfado. Ha triunfado un conglomerado de partidos que se... esté... figuran como unión popular, ¿mm? Ahora yo creo que será un gobierno - - - centro izquierdista, creo. (Corpus del Español; Habla Culta: Buenos Aires: M26 B). 
Como se muestra en el ejemplo anterior, yo creo que presenta una posición sintáctica inicial y creo, posición final. A pesar de que este segundo no tiene un cometido sintáctico dentro del complejo de cláusulas, creo realiza una evaluación epistémica que tiene alcance sobre toda la unidad precedente.

Los ejemplos de (yo) creo (que) que vamos a revisar a continuación nos permitirán comprobar que la interpretación del marcador puede ser meramente epistémica cuando el hablante plantea lo dicho como una posibilidad, con cierta duda, es decir, una aserción atenuada, ligada a la opinión, la creencia, el recuerdo, etc.:

(7) La ópera es algo que yo frecuenté desde niño. Creo que vi mi primera ópera a finales de los años cuarenta, en el Teatro de la Zarzuela, de Madrid. Fue "Boris Godunov", que me causó un impacto muy fuerte. También vi esa temporada "La Walkiria". (Corpus del Español; Entrevista $(A B C)$ : Autor: Rubio, José Luis).

(8) ¿Cómo llegó a esta orquesta, es diferente con ella su actividad respecto de la que realiza en Londres con la Royal Philharmonic? - Creo que fue hace siete u ocho años, dirigí un concierto como invitado e inmediatamente se me ofreció la dirección de la orquesta; yo me quedé muy impresionado y sorprendido. (Corpus del Español; Entrevista $(A B C)$ : Autor: Pérez de Arteaga).

(9) Nosotros estuvimos. Sí, sí. Es un buen hotel, sí. Inf. a —Era un lindo hotel. Ahora hay un hotel mucho mejor. Inf. b - ¿Ah sí? Inf. a - Aquel era muy bueno. Y la segunda vez - - - que fuimos - - - también - - - reservamos en... este... en ese hotel salteño que creo que se llama Gran Hotel T... eh... era... era de... de turismo. Inf. b —Sí. No sé. Era el de turismo. Todo lo [...]. Inf. a —Estuvimos muy bien, comimos muy bien. (Corpus del Español; Habla Culta: Buenos Aires: M26 B).

La duda puede expresarse junto con otras expresiones de suspensión de aserción o de evidencialidad, como se muestra en la tabla siguiente, aunque la coaparición entre estas y (yo) creo (que) no es significativamente frecuente $(15,87 \%)$ :

\begin{tabular}{|l|l|l|l|}
\hline caso 1 & yo no sé & caso 2 & creo \\
\hline caso 3 & ¿no? & caso 4 & no sé \\
\hline caso 5 & ¿no? & caso 6 & si no me equivoco \\
\hline caso 7 & puede que, no sé & caso 8 & ¿no? \\
\hline caso 9 & tal vez & caso 10 & ¿no? \\
\hline
\end{tabular}

Tabla 5. Diez casos de duda reforzada.

(10) Nosotros quedamos en el país... este... de Arnés, fuimos a la casa de los abuelos y después estuvimos en Pau, en Baña Ormigó, que mi padre alquiló allí una... una quinta, estuvimos ahí una temporada. Enc. — ¿Cuánto tiempo se quedaron? Inf. —Creo ... yo no sé porque era muy chico, yo tenía - - - cuatro o cinco años. (Corpus del Español; Habla Culta: Buenos Aires: M13 A). 
(11) No tengo más que este ejemplar y no me... no me quiero deshacer de la colección. Inf. —No, no, no, no, no, no, no. Si no lo tiene... si no lo tiene, sí. Enc. —Es decir, que se lo haré llegar - - - más adelante. Inf. —Claro. Enc. —Es este trabajo: Las [...] en la Argentina. Inf. —iQué bueno! Enc. —Y creo que, si no me equivoco... Inf. —Este seño... N., esta es la señorita. Enc. - M. N., eso. Inf. —Eso es. (Corpus del Español; Habla Culta: Buenos Aires: M33 B).

Cuando (yo) creo (que) se combina con una subordinación en futuro próximo, la interpretación es de intencionalidad. Pero en este contexto también puede denotar la posibilidad de que ocurra lo que se expresa: creo que tiene el mismo significado que las expresiones de posibilidad como es posible/probable que:

(12) Yo creo que se va a demorar por lo menos un año, año y medio. Es muy difícil, yo entiendo que en esta universidad hay unos ochocientos colaboradores. (Corpus del Español; Habla Culta: Bogotá: M21).

(13) — ¿Y ahora dónde... cuánto piensa durar su esposo? Inf. — ¿En Panamá? Enc. —Mjm. Sí. Inf. -Unas dos semanas, no más; sí, pero después regresa acá, y creo que en marzo va a los Estados Unidos, otra semana o dos semanas. Enc. - Pero genial, porque él sí viaja muchísimo, ¿no? Inf. — Sí, él viaja, pero eso es muy bueno porque se actualiza. (Corpus del Español; Habla Culta: Bogotá: M44).

Todos los ejemplos que hemos visto muestran el uso atenuante de (yo) creo (que) 1 cuando funciona como marcador de la actitud epistémica. Posee tentative function (Holmes 1990: 199) para expresar la inseguridad. Sin embargo, esta función se aplica también para "soften an assertion which may be too blunt" (Aijmer 1997: 21). A continuación, analizaremos (yo) creo (que) desde una perspectiva pragmática más amplia, al verlo como un marcador asociado con las relaciones interpersonales y la imagen del interlocutor.

\section{5. (YO) CREO QUE 2 COMO MODALIZADOR DE OPINIÓN}

Si bien (yo) creo (que) puede expresar una actitud epistémica de inseguridad sobre el contenido proposicional, este uso no está presente en muchas proposiciones en las que aparece esta expresión. En el siguiente ejemplo, cuesta aceptar que el hablante evalúe la probabilidad de que suceda el contenido de la oración subordinada. Al contrario, tiene seguridad sobre lo dicho:

(14) - Yo sí creo que la educación... que la familia es primordial (Corpus del Español; Habla Culta: Caracas: M13).

Como se muestra en el anterior ejemplo, con el uso del marcador creo que se da cierto efecto de mitigación, pero este efecto no se aplica en la esfera del enunciado, sino en la de enunciación.

Aijmer (1997: 20), en su estudio sobre la partícula modal I think, hizo mención de su función atenuante: "Epistemic qualifiers are used to avoid disagreement, to soften speech acts, or to express involvement. Using a term from Crystal-Davy (1975), we can refer to $I$ think as a "softener" or "softening connective". I think may, for example, be used to soften a blunt assertion". 
Tanto "avoid disagreement" y "soften speech acts", como "express involvement" son estrategias de cortesía que lleva a cabo (yo) creo (que) 2 a través de su función de modalizador de opinión. En esta actuación, se trata de un mecanismo para velar por la imagen social de ambas partes y está dedicado a la producción de efectos corteses en los intercambios verbales. El valor epistémico original de (yo) creo (que) puede conservarse o perderse completamente, lo cual tiene su causa en la cortesía. Igual que otras expresiones epistémicas que suspenden la aserción, (yo) creo (que) 2 suele experimentar una pérdida total del valor epistémico y se convierte en un elemento meramente cortés.

A continuación, basándonos en los resultados del Corpus, analizamos (yo) creo (que) 2 a partir de las siguientes funciones que ejerce en diferentes actos discursivos:

a) Atenuar el decir, que se plantea como una opinión, un juicio personal para evitar imponer la idea al interlocutor y dejarle opciones.

"Creo que la pintura de Picasso es demasiado abstracta".

b) Atenuar la fuerza ilocutiva, por ejemplo, mitigar un acto directivo.

"Creo que deberías dedicar más tiempo a los estudios".

c) Atenuar los efectos negativos de lo dicho, tales como un desacuerdo, una valoración negativa, etc.

"Yo creo que no, no es tan malo como tú dices".

"Creo que eres un poco imprudente esta vez".

d) Atenuar la valoración positiva sobre el hablante mismo, de forma que se da cierto efecto de modestia.

"Creo que soy muy buena en historia y geografía".

e) Intensificar la relación de alianza a través de la expresión de acuerdo y contenido favorable hacia el interlocutor.

"Creo que has definido muy bien las características de los dos partidos".

Se puede recurrir al uso atenuante de (yo) creo (que) 2 en los actos que se perciben como posibles conflictos para mitigar los efectos negativos y proteger la imagen social del interlocutor, aunque su uso no siempre consiste en evitar riesgos. Por ejemplo, pueden usarse para transmitir un contenido de modestia. Por otro lado, podemos fijarnos en su uso intensificador cuando nuestra intención es colaborar positivamente con el interlocutor, acercarnos a él y establecer una relación de alianza o intimidad.

\subsection{La expresión de opinión personal}

Sobre creo que, De Saeger (2006: 268) piensa que "tradicionalmente se postula que el sujeto/conceptualizador expresa su in(seguridad) frente al contenido proposicional en la oración subordinada. Este aspecto de modalidad epistémica no siempre es compatible con la expresión de opinión con la que estos verbos también han sido definidos". Esto corresponde a lo que planteamos antes, que no todos los casos de (yo) creo (que) poseen un significado epistémico, este marcador puede solo desempeñar una función argumental.

Como podemos ver en el Corpus, se ha registrado un gran número de ejemplos en los que (yo) creo (que) se usa para expresar el parecer en relación con un tema determinado, y en los cuales este marcador nos informa del parecer subjetivo del hablante, de su entendi- 
miento sobre algo. En los ejemplos siguientes, el hablante nos explica su propia definición sobre la pintura y el lenguaje. (yo) creo (que) nos informa de que lo dicho es una opinión, no una aserción tajante:

(15) Creo que la pintura es una máquina que le sirve al espectador para pensar y que la riqueza de la pintura está en su capacidad para sugerir. ¿Hay compromiso en el arte? El artista es notario, testimonia el momento. Al pintar, refleja lo que ve, lo que siente, imbuido de ese ambiente que le ha tocado vivir. (Corpus del Español; Título: Entrevista $(A B C)$ : Autor: Pajares, Gema).

(16) Yo creo que el lenguaje es ilímite, como son los números. El fondo pues está todo contenido; la humanidad no es sino una enredadera que da la vuelta a la misma espiral, va y viene, ideológicamente. Es mi concepto, por lo menos. (Corpus del Español; Habla Culta: Bogotá: M23).

(17) Creo que tanto los cristianos como los árabes y los judíos, comprendiéndose unos a otros, pueden aprender a compartir lo que debe ser compartido. (Corpus del Español; Título: Entrevista ( $A B C)$ : Autor: Rubio, José Luis).

En predicados como creer, la expresión de opinión es compatible con otros marcadores de modalidad epistémica. Por ello, son compatibles con adjuntos modales que expresan certeza, probabilidad o posibilidad:

(18) Creo que la más cuidada es, sin duda, "El huésped del sevillano”, pero también destacaría, por su labor de inmersión, "La rosa del azafrán". —El libro no es tan solo una biografía... (Corpus del Español; Título: Entrevista $(A B C)$ ).

En los siguientes ejemplos, la contradicción semántica es entendible. Por un lado, entendemos que el hablante no duda de lo enunciado. Por otro lado, no quiere ser tajante, quiere dejar opciones al interlocutor.

Cuando (yo) creo (que) 2 aparece con la partícula interrogativa ¿no?, el hablante intenta llamar la atención del interlocutor, mostrar respeto, con el fin de mantener el intercambio comunicativo:

(19) Ese régimen de evaluación yo creo que tiene sus... problemas y sus... ventajas, ¿no? Enc. - -... mm... Inf. B - - Porque en realidad el estudiante que es... que es bueno... es... es una... una buena posibilidad, pero... realmente, el otro estudiante, posiblemente... estudia muy parcializado, ¿ves? Enc. - -... si... Inf.- -. (Corpus del Español; Habla Culta: Caracas: M19).

(20) Yo creo que la revolución la tienen que hacer los revolucionarios, los obreros, los campesinos, ¿no?, concretamente. Creo que sí puede contribuir a... a plantear inquietudes. Muchas veces lo importante no es dar respuestas a todo. (Corpus del Español; Habla Culta: Bogotá: M11).

(21) —Yo... yo sí se las recomendaría, y creo que les serviría mucho. Inf. a — ¿Pero las... a las... de las de primero y segundo, o más grandecitas? (Corpus del Español; Habla Culta: Bogotá: M26). 
También se registran algunos casos de repetición de marcadores de opinión personal en los que se hace hincapié en la presencia de "yo" hablante. Son marcas como para mí, desde mi punto de vista, que refuerzan el valor de opinión. Con ellos entendemos que todo lo enunciado parte de un punto de vista subjetivo, no representa una idea general, y no hay intención de imposición:

(22) Creo que este hombre se comportó deshonestamente, desde mi punto de vista, y estaré encantado de que se publiquen estas declaraciones: este señor actuó de forma totalmente "amateur", sin un ápice de profesionalidad, y si hubiera tenido una pizca de respeto por sí mismo jamás debería haber aceptado la presidencia del Consejo, sabiendo que era un ignorante completo de todos los temas artísticos y musicales. (Corpus del Español; Título: Entrevista $(A B C)$ : Autor: Pérez de Arteaga, José Luis).

(23) El día que se acabe Colombia pues ya no, no hay materia de hacer historia; pero mientras Colombia exista está haciendo historia. Y esa historia hay que seguirla adelante. De modo que para mi yo creo que es un trabajo muy largo, bien meditado... (Corpus del Español; Habla Culta: Bogotá: M36).

También es frecuente encontrar casos en los que contiene alguna valoración o caracterización en el contenido de la proposición. En palabras de De Saeger (2006: 272):

Incluso cuando no hay signos evidentes de valoración en el contenido proposicional, la interpretación de opinión es posible, siempre cuando haya algún tipo de caracterización. Sin caracterización - por ejemplo, en identificaciones o clasificaciones- el predicado de actitud proposicional es más propenso a una modalización epistémica.

En todos los ejemplos de (yo) creo (que) 2, una totalidad de 132 casos, 41 incluyen valoraciones en la expresión de opinión (31\%). Cabe señalar que esta tendencia de uso está mucho más marcada en (yo) creo (que) 2, que expresa opiniones personales, que en dar evaluaciones sobre la veracidad de lo dicho. Veamos la tabla 6:

\begin{tabular}{|l|l|l|l|}
\hline caso 1 & importante & caso 22 & más grande \\
\hline caso 2 & nuevo & caso 23 & de extraordinaria importancia \\
\hline caso 3 & verdaderamente & caso 24 & incapaz \\
\hline caso 4 & especial & caso 25 & deshonestamente \\
\hline caso 5 & humana & caso 26 & interesante \\
\hline caso 6 & más democrático & caso 27 & la más cuidada \\
\hline caso 7 & beneficioso & caso 28 & infantil \\
\hline caso 8 & más grande que..., más importante & caso 29 & muy interesante \\
\hline caso 9 & mucho más & caso 30 & terrible \\
\hline caso 10 & fundamental & caso 31 & fundamental \\
\hline caso 11 & no es tan importante & caso 32 & fundamental \\
\hline caso 12 & de poco vuelo & caso 33 & original \\
\hline
\end{tabular}




\begin{tabular}{|l|l|l|l|}
\hline caso 13 & está en muy mal estado & caso 34 & profunda \\
\hline caso 14 & buen nivel & caso 35 & importante \\
\hline caso 15 & engañoso & caso 36 & ilímite \\
\hline caso 16 & mejores que & caso 37 & importantísimo \\
\hline caso 17 & increíblemente importante & caso 38 & primordial \\
\hline caso 18 & interesante & caso 39 & interesante \\
\hline caso 19 & vulnerable & caso 40 & fue un error \\
\hline caso 20 & importante & caso 41 & agresiva \\
\hline caso 21 & interesante & & \\
\hline
\end{tabular}

Tabla 6. Casos de expresión de opinión con valoración.

La mayoría de los casos que encontramos son valoraciones con adjetivos (tales como (increiblemente) importante, interesante, fundamental, original, bueno, primordial, etc.), o sintagma adjetival (de extraordinaria importancia):

(24) También existen algunos pensadores que se interesan en la música como fenómeno de pensamiento, y eso es algo nuevo. Yo creo que eso es importante. (Corpus del Español; Título: Entrevista $(A B C)$ : Autor: Rubio, José Luis).

(25) Me parece que la cantidad total de financiación se ha incrementado y las Universidades han empezado a hacerse más fuertes, mientras que sus investigadores se han ganado el respeto del Gobierno. En este sentido, creo que España tiene un buen nivel de desarrollo en ciencia. (Corpus del Español; Título: Entrevista $(A B C)$ : Autor: Aguirre de Carcer, Alberto).

Expresar valoración con los comparativos y superlativos:

(26) Personalmente, creo que la música de Elgar es más grande que la de Mahler. Mahler es un magnífico compositor, pero en su música hay mucho relleno. No debiera decir esto porque Mahler es un gran compositor, pero creo que Elgar es más importante. (Corpus del Español; Título: Entrevista $(A B C)$ : Autor: Puig, Valentí).

(27) Soy un adicto a Chopin. Creo que es el más grande compositor para piano del siglo XIX. (Corpus del Español; Título: Entrevista $(A B C)$ : Autor: Rubio, José Luis).

Las valoraciones pueden ser positivas, neutras y también negativas:

(28) Los artistas que quieren seguir insistiendo en que es muy bonito saber copiar los melocotones o la batalla de Tetuán, pues que lo hagan. Yo creo que son artistas de poco vuelo y no aportan nada nuevo a la historia del arte. Los artistas deben ser juzgados por lo que aportan de nuevo y por cómo afrontan la realidad. Estudiar la realidad. (Corpus del Español; Título: Entrevista $(A B C)$ : Autor: Calderón, Manuel).

(29) Creo que Franco era incapaz de verse a sí mismo críticamente, y le gustaban muchos elementos de su propio mito. (Corpus del Español; Título: Entrevista $(A B C)$ : Autor: Fusi, Juan Pablo). 
Según lo que hemos visto, los ejemplos son opiniones del hablante con valoraciones que no afectan a la imagen social del interlocutor. En estos casos, la función de (yo) creo (que) consiste en introducir una opinión no tajante y en la que el hablante muestra su intención de no imponer la idea a su interlocutor. Además, (yo) creo (que) puede usarse para generar efectos atenuantes en el caso de que el hablante pretenda ser cuidadoso con las valoraciones negativas que ha hecho, como ocurre en los dos últimos ejemplos. Por otro lado, si las valoraciones tienen efectos en la imagen social del interlocutor, (yo) creo (que) tiene:

- Valor atenuante cuando las valoraciones no son favorables para la imagen del interlocutor.

Y puede tener:

- Valor intensificador cuando las valoraciones son favorables para la imagen del interlocutor.

El propio hecho de no afirmar con fuerza es atenuación, sea en los casos de expresión de duda o de opinión. Sin embargo, su valor no solo se limita a la mitigación. En "Yo creo que lo que dices tiene toda la razón", se genera un efecto de intensificación. La construcción yo creo que no enfoca en lo dicho con añadir o quitar peso a la veracidad sobre el contenido proposicional: lo que dices tiene toda la razón. Sino más bien con la clara implicación del hablante, en este caso, expresar un acuerdo con lo dicho por su interlocutor, la tentative function de yo creo que se convierte en deliberative function, ya que, según Aijmer (1997: 22), este último atañe a la cortesía positiva y apoya a dar rapport. Aquí estamos hablando de un esfuerzo para la imagen positiva del interlocutor y un refuerzo de los lazos sociales entre ambas partes.

Esta función no solo aparece en la expresión de acuerdo, sino que también se activa en actos como una valoración positiva dirigida al receptor:

(30) Creo que has definido muy bien las características de los dos partidos, avanzando pero conservando todas las grandes cualidades que tenía y tiene la República, y en cambio el partido liberal avanzaba desdeñando un poco aquellas cosas antiguas que nos habían dejado las épocas anteriores. (Corpus del Español; Habla Culta: Bogotá: M36).

Con el ejemplo anterior, podemos ver que, pese a la falta del pronombre yo en la construcción de creo que, la implicación del hablante sigue existe y su intención de reforzar la imagen positiva del interlocutor sigue siendo muy evidente.

Por otro lado, cabe señalar que (yo) creo (que), cuando introduce valoraciones positivas hacia el interlocutor, no siempre denota un valor intensificador ya que la interpretación tanto semántica como pragmática depende siempre de cada contexto concreto. Sin más contexto, (yo) creo (que), puede reflejar un continuo de posibilidades. Pero lo que está fuera de toda duda es que la presencia del marcador (yo) creo (que), en muchos casos, funciona como una señal de alianza y el hablante lo puede usar estratégicamente como mecanismo de cortesía, sea con sujeto explícito o elíptico. 


\subsection{Atenuar el desacuerdo}

Una opinión es mucho más que un punto de vista personal. Muchas veces, lo que opinamos afecta a la relación con las personas que reciben esta respuesta. La expresión epistémica de opinión tiene la función pragmática de proteger la imagen social del interlocutor.

(31) - Pero que después no tienen cultura.

- Bueno, yo creo que quizás aquí, en esta ciudad, esto esté entrando ahora más.

- ¿El interés cultural?

- Sí. Yo creo que en estos últimos años... Bueno, quizás sea una cosa general, de todas las ciudades, pero quizás aquí esté entrando más ahora. (Corpus del Español; Habla Culta: Lima: M9).

Como se muestra en el ejemplo anterior, el desacuerdo se introduce mediante bueno. Para atenuar este desacuerdo, el hablante opta por expresar una opinión personal a través de (yo) creo (que) 2 ante lo dicho, así que no actúa en contra del receptor. En este caso, el emisor se implica personalmente en el enunciado con un verbo epistémico en primera persona de singular. El hablante elige mitigar el efecto de sus palabras aplicando una estructura de opinión que encabeza la frase. Mediante esta estructura, declara que lo dicho es puramente una perspectiva personal y respeta la opinión de su receptor. Además, aparece un quizás con el que se crea una sensación de inseguridad, de que el hablante puede estar equivocado sobre lo dicho. Por consiguiente, el emisor muestra cierta flexibilidad en la negociación y deja opciones al interlocutor.

\subsection{Dar una sugerencia personal}

Con (yo) creo (que) se atenúan los actos directivos y disminuye la fuerza de la afirmación. Es decir, el hablante intenta no agredir el campo del otro, no pretende imponer a los demás que acepten su propuesta. No es un mandato, sino una sugerencia personal. Por consiguiente, sostenemos que creo que ejerce cierta función que protege la imagen social del receptor y, a la vez, salvaguarda la del hablante mismo. Como se muestra en la siguiente tabla, hemos encontrado una total de 12 expresiones de la sugerencia personal combinadas con otros mecanismos atenuantes:

\begin{tabular}{|l|l|l|l|}
\hline caso 1 & debería & caso 2 & debe \\
\hline caso 3 & debería & caso 4 & deberían \\
\hline caso 5 & deberían & caso 6 & deberían \\
\hline caso 7 & habría que & caso 8 & podría \\
\hline caso 9 & deberíamos & caso 10 & se deberían \\
\hline caso 11 & debemos & caso 12 & debemos \\
\hline
\end{tabular}

Tabla 7. Expresión de sugerencia mitigada. 
(32) Un peligro evidente es que la información genética pueda ser utilizada para discriminar injustamente a cierto tipo de personas. Creo que es algo que debe estar muy regulado por la legislación. (Corpus del Español; Título: Entrevista $(A B C)$ : Autor: Aguirre de Carcer, Alberto).

(33) Yo creo que el PP debería protestar, incluso ante los tribunales, cada vez que la televisión y la prensa estatales le tildan de "conservador". (Corpus del Español; Título: Entrevista $(A B C)$ : Autor: Semprún Maura, Carlos).

\section{4. (Yo) creo que como recurso de modestia}

(Yo) creo (que) 2 también puede usarse como estructura de cortesía para transmitir un contenido de modestia. De nuevo esto exige que la referencia vaya dirigida al propio yo hablante y que aparezcan contenidos de valoración positiva en puntos elevados de la escala. Por ejemplo, en (34) se habla de ser compositor, una carrera muy valorada, en (35) de conocer bien la cultura y en (36) de valorar los propios trabajos:

(34) — ¿Ha hecho usted carrera como compositor? —-Modestamente, creo que sí. Ha sido más de medio siglo de dedicación plena a la música y además con la satisfacción de que, llegado a los ochenta años, estoy recibiendo más atenciones y deferencias que en cualquier otro momento de mi vida. (Corpus del Español; Título: Entrevista $(A B C)$ : Autor: Codina, Jordi).

(35) Sí, soy español, me siento perteneciente a mi cultura. Conozco a los clásicos españoles, y los leo. Creo que conozco la cultura bastante bien. Y además, me interesa: si no, no tendría, por ejemplo, la colección de partituras de zarzuela que tengo. (Corpus del Español; Título: Entrevista $(A B C)$ : Autor: Rubio, José Luis).

(36) ... habido en América Latina, digamos década del veinte y del treinta, grandes reporters - - - grandes reporters... Inf. —Bueno, claro. Enc. —... esté... que en la actualidad - - no los hay porque es la... es la crisis, digamos. Inf. —-No. Enc. —... más que nada de las instituciones periodísticas mismas. Inf. -Exactamente, no te lo dejan hacer. Enc. -Exacto. Entonces yo he publicado algunos - - - que creo que son buenos, sobre temas muy variados que - - - en fin, no... (Corpus del Español; Habla Culta: Buenos Aires: M31 B).

En los tres ejemplos citados, el hablante ha hecho valoraciones positivas de sí mismo y creo que viene en apoyo de la expresión de modestia. Sin este marcador, la imagen social del hablante no es nada favorable para él si lo que pretende es ser cortés y aceptado por los demás. Las expresiones epistémicas atenuantes pueden ser recursos eficaces para evitar pareceres arrogantes y engreídos.

\subsection{Yo sí creo que y yo creo que sí}

El valor intensificador se adquiere cuando la construcción yo creo que se combina con ciertos elementos intensificadores. En este caso, tanto la posición personal sobre la opinión expresada como la fuerza ilocutiva de la sugerencia quedan reforzadas. Aquí hemos de diferenciar el valor atenuante-intensificador de yo creo que sí y yo sí creo que. 
El contenido proposicional puede ser modalizado epistémicamente para mostrar más seguridad o para quitar el valor de certeza, sea por motivo de cortesía o de inseguridad:

(37) Yo creo que sí han subido las denuncias de violencia y esto habla de que más mujeres están tomando consciencia, un tema que no se puede seguir naturalizando (Corpus del Español; Caracol Televisión).

En este caso, la actitud del hablante sigue siendo no tajante, es decir, el valor atenuante de yo creo que se conserva, ya que el marcador afirmativo sí solo ejerce una influencia en el contenido modificado: han subido las denuncias de violencia. El hablante se muestra más comprometido con la verdad de lo dicho, pero sigue intentando evitar la sensación de imposición.

La interpretación cambia cuando elementos intensificadores como sí, firmemente, con firmeza, etc., modifican la misma estructura yo creo que en lugar del contenido proposicional.

(38) ¿Saben por qué me importa la causa palestina? Porque yo sí creo que todos merecemos derechos humanos básicos iguales, bajo la misma ley internacional (Corpus del Español; Montevideo Portal).

(39) Yo creo firmemente que la policía solo debe intervenir en las escuelas para prevenir actos criminales, no para resolver problemas disciplinarios menores (Corpus del Español; ElTiempo.com).

El conjunto yo creo firmemente que / yo sí creo que / yo creo con firmeza que adquiere un valor intensificador y entendemos que el hablante quiere dejar una opinión contundente. No espera que esta sea refutada.

\section{CONCLUSIONES}

La forma performativa del verbo creer tiene dos significados básicos: creencia/evidencia insuficiente y actitud/opinión personal. Basándonos en esta diferencia, hemos analizado dos interpretaciones de (yo) creo (que): modal epistémico y modalizador de opinión. Puede actuar como nuclear de la oración (yo creo que) o marcador (creo, yo creo, creo yo) al poseer una interpretación completamente epistémica. El análisis del Corpus nos permite llegar a la conclusión (tabla 8) de que la función pragmática atenuadora en la forma performativa del verbo creer se aplica tanto en la modalidad epistémica como en la expresión de opinión, aunque en este último uso yo creo que puede tener función intensificadora:

\begin{tabular}{|l|l|}
\hline $\begin{array}{l}\text { (yo) creo (que) } 1 \\
\text { Modal epistémico } \rightarrow\end{array}$ & Enfocado a lo dicho: uso atenuante (suspender la aserción). \\
\hline $\begin{array}{l}\text { (yo) creo (que) } 2 \\
\text { Modalizador de opinión } \rightarrow\end{array}$ & $\begin{array}{l}\text { Enfocado al decir: uso atenuante (cortesía mitigadora): expresar opi- } \\
\text { nión personal, atenuar desacuerdo, dar sugerencia personal, expresar } \\
\text { modestia, etc. } \\
\text { Uso intensificador (cortesía valorizante): indicar opinión favorable al } \\
\text { interlocutor. }\end{array}$ \\
\hline
\end{tabular}

Tabla 8. Dos interpretaciones de (yo) creo (que) y su uso atenuante-intensificador. 
A diferencia de otras expresiones epistémicas (quizás, posiblemente, etc.), (yo) creo (que) está más restringida a la esfera personal. La presencia de "yo" en la escena comunicativa no solo transmite un punto de vista subjetivo, sino que genera ciertos efectos comunicativos que podrían afectar a la relación interpersonal entre el hablante y su interlocutor. (Yo) creo (que), cuando se usa como modalizador de opinión, pierde su matiz epistémico completamente en muchos contextos comunicativos y funciona como simple mecanismo de cortesía. Se relaciona con la cortesía mitigadora y funciona principalmente como atenuante que protege la imagen social del interlocutor al subsanar el enfrentamiento en actos refutativos ${ }^{7}$, al quitar la fuerza ilocutiva en actos directivos, etc. Su principal estrategia consiste en hacer hincapié en la presencia del "yo" e introducir lo dicho como opinión personal para evitar ser tajante y la sensación de imposición, ya que cualquier afirmación puede suponer un riesgo tanto para la imagen positiva del hablante (por dar informaciones erróneas) como para la negativa del interlocutor (por sentirse forzado a aceptar o consentir lo que plantean otros). La expresión de opinión se consideraría una estrategia de la cortesía y, por supuesto, la expresión (yo) creo que es un recurso que lleva a cabo dicha estrategia. Por otro lado, hemos comprobado que esta expresión, que se usa para suspender la aserción e indicar un bajo grado de certeza, puede adquirir un valor intensificador en muchos contextos y se usa para aproximarse a las expectativas del interlocutor. Se trata de un recurso para la cortesía valorizante, igual que otros típicos recursos epistémicos que refuerzan la aserción (claro, seguro, etc.).

Sin más contextos, (yo) creo (que) puede tener unas cuantas posibilidades de interpretación. Que tenga una u otra es una cuestión cuya respuesta está en cada contexto comunicativo. Además de los aspectos contextuales, los aspectos formales son también indicios lingüísticos que contribuyen a que entendamos la intención comunicativa del hablante. Con el presente trabajo hemos podido comprobar que (yo) creo (que) 1 solo se combina con marcadores que indican suspensión de la aserción (quizás, tal vez, etc.) y el conjunto atenúa la certeza del contenido proposicional. Por su parte, hay casos en los que (yo) creo (que) 2 aparece tanto con los de suspensión de la aserción - para ser menos tajante con la opinión, reducir aún más la fuerza ilocutiva, etc.- , como con otros de refuerzo de la aserción (realmente, sí, etc.), con el fin de poner énfasis a sus palabras o explicar su clara posición respecto al contenido o, incluso más allá, su apoyo hacia el interlocutor. Además, podemos ver que hay casos en los que las tendencias de uso de una u otra forma lingüística no son siempre muy marcadas. Es decir, elegir una u otra forma no condiciona una interpretación predominante del uso de (yo) creo (que), tal puede ser el caso de la expresión de sugerencia ${ }^{8}$. Por otro lado, hay algunas tendencias de uso muy claras. La formulación del sujeto yo se asocia más a (yo) creo (que)2, que representa el $59 \%$ de la totalidad de ejemplos de expresión de opinión, ya que es en este caso en que el hablante se inclina a dejar sus huellas. Mientras este porcentaje baja al $30 \%$ cuando (yo) creo (que) 1 indica evaluación epistémica, en cuyo caso el hablante se aleja de la responsabilidad de la verdad de lo dicho. Además, los datos muestran que las valoraciones acompañan generalmente a la expresión de opinión y la modestia se expresa con una significativa frecuencia con sujeto elíptico.

7 Son aquellos actos en los que se contradice la opinión del interlocutor.

8 El porcentaje de los casos de omisión del sujeto y el de los de expresión del sujeto son similares. 


\section{REFERENCIAS BIBLIOGRÁFICAS}

Aijmer, K. (1997). “I think -an English modal particle”. En Swan, T. y O. J. Westvik (eds.), Modality in Germanic languages: Historical and comparative perspectives. Berlín: Mouton De Gruyters, pp. 1-48.

Aijón Oliva, M. Á. y Serrano, M. J. (2010). "El hablante en su discurso: expresión y omisión del sujeto de creo", Oralia: Análisis del discurso oral, (13), pp. 7-38.

Albelda Marco, M. y Cestero Mancera, A. M. (2011). "De nuevo, sobre los procedimientos de atenuación lingüística", Español actual: Revista de español vivo (96), pp. 9-40.

Arndt, H. (1987). "Speech functions, cooperation and competition in dialogue". Paper presentado en Conference on Language and power, Bellagio, Italia.

Borrego, J., Asencio, J. J. G. y Prieto, E. (1990): El subjuntivo. Valores y usos. Madrid: SGEL.

Brown, P., y Levinson, C. S. (1987). Politeness: Some Universals in Language Usage. Cambridge: Cambridge University Press.

Calsamiglia, H., y Tusón, A. (2012). Las cosas del decir: manual de análisis del discurso. Barcelona: Ariel.

Carrasco Santana, A. (1999). "Revisión y evaluación del modelo de cortesía de Brown y Levinson". Pragmalingüística (7): 1-44.

De Saeger, B. (2006). "Evidencialidad y modalidad epistémica en los verbos de actitud proposicional en español”, Interlingüistica (17), pp. 268-277.

Fuentes Rodríguez. C. (2010a). "La aserción parlamentaria: de la modalidad al metadiscurso", Oralia, 13, pp. 97-125.

Fuentes Rodríguez, C. (2010b). La gramática de la cortesía en español/LE. Madrid: Arco Libros.

García Miguel, J. M., y Comesaña, S. (2004). "Verbs of cognition in Spanish: Constructional schemas and reference points", Estudos de Linguística Cognitiva, vol. 1, pp. 399-420.

Haverkate, H. (1994). La cortesía verbal: estudio pragmalingüístico. Madrid: Editorial Gredos.

Holmes, J. (1990). "Hedges and boosters in women's and men's speech", Language \& Communication, 10 (3), pp. 185-205.

Hooper, J. B. (1975): “On assertive predicates”. En Kimball, J. (ed.), Syntax and Semantics, vol. IV. Nueva York: Academic Press, pp. 91-124.

Kerbrat-Orecchioni, C. (1996). La conversation. París: Seuil.

Meyer-Hermann, R. (1988). "Atenuación e intensificación (análisis pragmático de sus formas y funciones en español)", Anuario de estudios filológicos (11), pp. 275-290.

Soler Bonafont, M. A. (2018). "Fingimientos y atenuación en el uso de "creo"”, RILCE. Revista de Filología Hispánica, 34 (3), pp. 1104-1128.

Yu Xie (2017): Recursos lingüísticos de la modalidad epistémica y sus paralelos en chino. Tesis doctoral, Sevilla: Universidad de Sevilla. 
